\title{
REINAÇÕES DE NARIZINHO EN ESPAÑOL, UNA PROPUESTA: PROYECTO CHILENO DE TRADUCCIÓN Y ANÁLISIS COMPARATIVO DE TRADUCCIÓN LATINOAMERICANAS
}

\author{
Letícia Maria Vieira de Souza Goellner 1 \\ Pablo Saavedra ${ }^{1}$ \\ Vicente Menares ${ }^{1}$ \\ 'Pontificia Universidad Católica de Chile, Santiago, Chile
}

\begin{abstract}
Resumen: El propósito de este artículo es presentar una discusión sobre las posibilidades de traducción al español de la obra Reinações de Narizinho (1931) de Monteiro Lobato, cotejando seis traducciones distintas de algunos cuentos presentes en esta edición. Fueron seleccionadas para este estudio y cotejo las traducciones publicadas en Chile el año 2020, en Perú el 2019, dos ediciones colombianas de ese mismo año y dos versiones argentinas, una de 1944 y la otra de 2010. Exhibiremos algunos ejemplos que podrían ilustrar las estrategias usadas en nuestro proceso de traducción en Chile el cual buscó la aproximación del lector a la cultura fuente. Este análisis se enfoca en los neologismos, la estructura, el ritmo, y los culturemas presentes en la obra.
\end{abstract}

Palabras clave: Literatura infantil; Monteiro Lobato; Traducción literaria; Traducción latinoamericana; Travesuras de Naricita

\section{AN APPROACH TO REINAÇÕES DE NARIZINHO IN SPANISH: A CHILEAN TRANSLATION PROJECT AND COMPARATIVE ANALYSIS OF LATIN AMERICAN TRANSLATIONS}

Abstract: The objective of this article is to present a discussion about the possibilities of translating into Spanish the book Reinações de Narizinho (1931) by Brazilian author Monteiro Lobato by comparing six different 
translations of some of the stories in this publication. For this study and the comparison, one translation made in Chile in 2020, one in Peru in 2019, two made in Colombia the same year, and two made in Argentina (1944 and 2010) were selected. We will provide some examples in order to illustrate the strategies we used during our process of translation for the Chilean edition, which aimed at taking the reader closer to the source culture. This analysis is focused on neologisms, structure, rhythm, and the culturemes found in the book.

Keywords: Children's Literature; Monteiro Lobato; Literary Translation; Latin American Translation; Narizinho

\section{Breve introducción a la traducción de Lobato en ediciones de Argentina, Perú, Colombia y Chile}

El objetivo de este artículo es presentar una discusión sobre las posibilidades de traducción al español de la obra Reinações de Narizinho de Monteiro Lobato, así como compartir nuestra propuesta de traducción de una selección de los cuentos de este libro. El punto de partida de estas reflexiones es una edición traducida de la obra y publicada en Chile (Lobato, 2020). El lanzamiento de esta traducción coincidió con la celebración de los 100 años de la creación de los personajes de Naricita, Emília, Tía Anastácia y Dona Benta, entre otros personajes clásicos de la literatura infantil brasileña que dividen el espacio del mundo ficticio de la Parcela del Pájaro Carpintero Amarillo. El equipo de traductores, compuesto por una brasileña y dos chilenos, trabajó durante el 2019 en las características esenciales para la ejecución del trabajo ${ }^{1}$. La idea era traducir el texto $A$ menina do narizinho arrebitado (La niña de la naricita respingada) de 1920 y posteriormente agregar otros

${ }^{1}$ El proyecto fue presentado el 2020 y se adjudicó un fondo del concurso en la línea de investigación del concurso CCA- Creación Artística, Modalidad Profesional, coordinado por la Dirección de Artes y Cultura (DAC), https:// vicerrectoriadeinvestigacion.uc.cl/Artes-y-Cultura/creacion-y-cultura-artistica. html, concurso anual y abierto a toda la comunidad académica de la Pontificia Universidad Católica de Chile. 
cuentos presentes en el libro Reinações de Narizinho de 1931 (para este estudio ocupamos como texto fuente la edición organizada por Marisa Lajolo (2019) [1931]).

El propósito principal del grupo de investigadores era presentar un proyecto de traducción que pudiese contribuir y reforzar la inserción de la cultura brasileña en Chile a través de la literatura infantil y destacar mediante la obra la aceptación y reconocimiento del Otro como otro, valorando sus diferencias. Creemos que la traducción puede facilitar, mantener y crear puentes con el Otro y en esta línea fuimos elaborando y discutiendo las estrategias de traducción para alcanzar nuestro objetivo.

A continuación, presentaremos un breve panorama de las obras del autor brasileño publicadas en lengua española $\mathrm{y}$, específicamente, sobre la obra Reinações de Narizinho que ya fue traducida y publicada en Argentina ${ }^{2}$, Perú y Colombia.

Los textos de Lobato circularon ampliamente en Argentina durante las primeras décadas del siglo pasado. El contacto constante entre el autor y los intelectuales, editores y escritores de ese país posibilitaron distintos tipos de relaciones profesionales, que tenían como objetivo principal, e inicial, establecer un intercambio literario entre los escritores de ambos países. En el caso de Lobato, que además de autor era un importante visionario del mundo editorial, se utilizaron varias tácticas de publicación que permitieron que sus textos marcasen presencia en el territorio rioplatense por décadas. Unas de esas fue la publicación de fragmentos de sus obras, cuentos independientes, artículos y ensayos en colaboración con revistas argentinas, además de obras publicadas íntegramente por las editoriales locales. Este tipo de relación con Argentina le permitirá escribir una larga historia de publicaciones desde 1920, comenzando con Urupês, traducido por Benjamín de Garay.

\footnotetext{
${ }^{2}$ Destacamos que la explicación sobre Lobato en Argentina es más extensa que las demás debido a su largo historial de publicaciones en el país, algo que no ocurrió en los demás países aquí mencionados. Además, Argentina fue el único país a publicar su obra infantil completa traducida al español.
} 
Por motivos de extensión nos limitaremos a destacar una cita de la Dra. Thaís Albieri (2009) ${ }^{3}$, especialista en la trayectoria de Lobato en Argentina, quien refuerza la importancia del creador en el país rioplatense:

Se Lobato já era conhecido na Argentina desde a década de 1920, por seus contos publicados na imprensa Sítio e por seu livro Urupês, na década de 1930 e 1940, o escritor será reconhecido, também, por suas obras infantis. Em 1938, Garay abriu as portas para que esse reconhecimento acontecesse na Argentina; porém, quem continuou com a trajetória de publicações lobatianas, a partir de 1942, foi Juán Ramón Prieto. As "portas literárias” de Monteiro Lobato estavam abertas na Argentina; no Brasil" (Albieri, 2009, p. 220)

A partir de ahora nos enfocaremos específicamente en Reinações de Narizinho, ya que se trata del principal objeto de análisis de este artículo. Además, presentaremos una breve descripción de cinco ediciones publicadas en español entre 1944 y 2019, las cuales serán exploradas en este estudio en comparación con la edición chilena.

El gran apogeo de la literatura infantil de Lobato en Argentina ocurrió en las décadas de los 30 y, principalmente, de los 40, al firmar un contrato con la Editorial Americalee, la cual publicó su obra infantil completa en 23 volúmenes. Hemos seleccionado para el análisis en este estudio la primera edición argentina de Reinações de Narizinho traducida por Ramón Prieto ${ }^{4}$ en 1944 a la que se suman cuatro ediciones publicadas en el siglo XXI: una de ellas

\footnotetext{
${ }^{3}$ Para todos los detalles, ver tesis de doctorado: São Paulo-Buenos Aires: a trajetória de Monteiro Lobato na Argentina (Albieri, 2009). Asimismo, agradecemos su generosidad académica y por facilitarnos otros materiales de Lobato referentes a su investigación.

${ }^{4}$ La edición completa puede ser encontrada a través del link: https://digital.bbm.usp. $\mathrm{br} / \mathrm{handle} / \mathrm{bbm} / 7473$. Posteriormente varias otras ediciones surgieron en Argentina.
} 
también Argentina (Lobato, 2010), la cual contó con el apoyo de la Embajada de Brasil en Buenos Aires; una peruana (Lobato, 2019a), que a su vez contó con el apoyo de la Embajada de Brasil en Lima; una colombiana publicada en junio (Lobato, 2019b) por la Dirección de Artes del Ministerio de Cultura de Colombia y una segunda versión colombiana de octubre (Lobato, 2019c), publicada por el Instituto Distrital de las Artes - Idartes.

Reinações de Narizinho, que ya contaba con su primera traducción de 1944 en el país rioplatense, volvió a ser publicada en el siglo XXI en ese mismo país, precisamente en el 2010, por la Editorial Losada. Esta edición presenta en créditos de traducción al mismo Ramón Prieto, sin embargo, no precisa la información sobre el origen y autoría de esta reedición. Cuenta además con un prólogo de Cristina Kirchner, y forma parte de un programa de apoyo a la traducción de obras brasileñas patrocinado por la embajada de Brasil en Buenos Aires. Están presentes en este volumen, de forma íntegra conforme a la edición y la cantidad de textos de la edición en portugués, los siguientes capítulos ${ }^{5}$ : Naricita Respingada ${ }^{6}$ (Narizinho arrebitado), La quinta del Benteveo (O Sítio do Picapau Amarelo), El marqués de Rabicó (O marqués de Rabicó), El matrimonio de Naricita (O casamento de Narizinho), Las aventuras del Príncipe (As aventuras do Príncipe), El gato Félix (O gato Félix). Al compararla con las otras ediciones

\footnotetext{
${ }^{5}$ En este artículo trataremos por "capítulos" cada historia original que aparece en la edición en portugués de Reinações de Narizinho, teniendo en cuenta que cada capítulo ofrece un número diferenciado de historias/cuentos. Recordando que los dos primeros capítulos sobre los cuales haremos referencia están configurados de esta manera Capítulo: historias. Cap 1. Narizinho Arrebitado: 1. Narizinho, 2. Uma Vez..., 3. No Palácio, 4. O Bobinho, 5. A Costureira das Fadas, 6. A Festa e o Major, 7. A Pílula Falante. Cap 2. O Sítio do Picapau Amarelo: 1. As Jabuticabas, 2. O Enterro da Vespa, 3. A Pescaria, 4. As Formigas Ruivas, 5. Pedrinho, 6. A Viagem, 7. O Assalto, 8. Tom Mix, 9. As Muletas do Besouro, 10. Saudades, 11. A Rainha, 12. A Volta

${ }^{6}$ Presentamos los títulos de la edición argentina en cursiva y títulos originales entre paréntesis.
} 
contemporáneas ${ }^{7}$ analizadas en este artículo, esta es la que presenta más cuentos traducidos en su totalidad, pues contiene 6 capítulos completos de los 11 pertenecientes a la edición original de Reinações de Narizinho en portugués.

Saliendo de Argentina, donde el autor ya es reconocido como escritor importante, partimos para otras traducciones más recientes al español que se publicaron en Perú y Colombia en el año de 2019.

En Perú, fueron publicados algunos cuentos de la obra Reinações de Narizinho en el marco de la FIL Lima -Feria Internacional del Libro de Lima, como parte de un proyecto cultural coordinado por la Embajada de Brasil en aquel país. Esta edición cuenta con una breve presentación del embajador de Brasil en Perú, Rodrigo Baena Soares, y se publicó en julio de 2019 por Cantarera editores, que recibe los créditos de traducción sin mencionar el nombre del traductor específicamente, diferente de lo que sucede con las obras traducidas y publicadas en Argentina y las dos ediciones en Colombia, en las cuales el traductor es indicado explícitamente. En la edición peruana son publicados de manera integral los dos capítulos iniciales ${ }^{8}$ de Reinações de Narizinho, o sea, cap. 1 Naricita Respingada (Narizinho arrebitado) y cap.2 El rancho del pájaro carpintero amarillo (O Sítio do Picapau Amarelo).

En Colombia hay dos publicaciones también del año 2019. Uno de los proyectos de traducción fue impulsado por la Dirección de Artes del Ministerio de Cultura de Colombia ${ }^{9}$ (junio de 2019, de aquí en adelante nos referiremos a esta edición como Colombia (1) y culminó en la publicación de Las travesuras de Naricita en una colección titulada Leer es mi cuento $^{10}$, un programa cultural

\footnotetext{
${ }^{7}$ La edición de 1944 publicó el libro completo con los 11 capítulos y todas sus historias.

${ }^{8}$ Presentamos los títulos de la edición peruana en cursiva y títulos originales entre paréntesis.

9 MaguaRED es parte de la Estrategia Digital de Cultura y Primera Infancia, proyecto de la Dirección de Artes del Ministerio de Cultura https://maguared. gov.co/las-travesuras-de-naricita/.

${ }^{10} \mathrm{https}$ ///reddebibliotecas.org.co/sala-lectura/colecci\%C3\%B3n-leer-es-mi-cuento.
}

Cad. Trad., Florianópolis, v. 41, n⿳2 2 p. 221-246, mai-ago, 2021. 
"que adelanta el Gobierno Nacional a través de sus Ministerios de Educación y Cultura, en una búsqueda por integrar la lectura y la escritura a la vida cotidiana de los colombianos, para promover las competencias que les permitan participar activamente en la sociedad actual". Esta edición no cuenta con una introducción o prólogo y presenta la traducción exclusivamente del primer capítulo de la obra: Naricita Respingada (Narizinho Arrebitado) y forman parte de esta selección de cuentos del primer capítulo las seis historias iniciales (para completar el capítulo 1 de manera integral falta apenas la historia "A pílula falante", que es justamente cuando Lobato da voz a la muñeca Emilia). La traducción es de Elkin Obregón ${ }^{11}$, un destacado caricaturista antioqueño que como periodista, narrador, poeta, editor, traductor y también ha sido investigador de la música brasileña.

Siguiendo con las publicaciones de Reinações de Narizinho en Colombia, otra iniciativa aún más reciente (octubre de 2019; de aquí en adelante nos referiremos a esta edición como Colombia 2) surgió a través de una nueva traducción, esta vez bajo el título Naricita impertinente y La casa del pájaro carpintero amarillo. Se trata de un proyecto apoyado por El Instituto Distrital de las Artes - Idartes, que funciona como "gestor de las prácticas artísticas en Bogotá”. Aquí, la traductora es Mariana Serrano Zalamea, profesora, investigadora y traductora. Esta edición cuenta con una breve presentación sobre Lobato escrita por Antonio García Ángel, y nos ofrece los dos primeros capítulos de la obra.

\section{Perspectivas y reflexiones teóricas sobre el desarrollo del proyecto Las travesuras de Naricita}

Este proyecto parte de la premisa de que la literatura infantil y su traducción no son géneros menores, a diferencia de cómo se

${ }^{11}$ Elkin Obregón falleció en enero de 2021.https://www.radionacional.co/noticia/ cultura/fallecio-caricaturista-escritor-elkin-obregon.

Cad. Trad., Florianópolis, v. 41, n⿳2 2 p. 221-246, mai-ago, 2021. 
entendía en otras épocas. De hecho, en un pasado no muy lejano las investigaciones sobre la traducción literaria infantil eran escasas.

Durante el desarrollo del proceso de traducción de Las travesuras de Naricita y la preparación de los ensayos finales, nuestra reflexión trascendió la preocupación por la transparencia y fluidez del texto de llegada, las cuales son actitudes generalmente pautadas por el encargo y la priorización del sentido y el público receptor. Desde el inicio establecimos preguntas referenciales que nos conducirían por un camino en busca de la extranjerización del texto traducido, concepto entendido a partir de la dicotomía domesticar-extranjerizar que, si bien se estableció hace siglos, adquirió esta nomenclatura y componente político a partir de Venuti en los años 90. Partimos de un concepto teórico amplio y muy debatido en la traductología relacionado con los textos literarios y que no está orientado específicamente a la literatura infantil, pero que nos sirvió para establecer algunas bases y guiar nuestras reflexiones y elecciones durante la traducción.

La complejidad de traducir literatura infantil radica en varios factores, y uno de ellos puede ser la función múltiple que desempeña el género que circula en los sistemas literarios y sociales. Todas estas interrogantes ya han sido ampliamente exploradas en el campo traductológico y literario, y debido a este enredo de factores la traducción literaria dirigida al público infantil nos obliga, como investigadores, a repensar el ejercicio de la traducción al abordar un texto para niños y niñas en un contexto extranjero.

Un aspecto relevante que se discutió es la gran libertad que se toma, generalmente, en las traducciones de textos infantiles con el fin de ajustarlos a la cultura receptora, ya sea por razones educacionales que son convenientes para la cultura extranjera, o por considerarlo un género sin mucho prestigio y, por lo tanto, más "adaptable" y "domesticable", como se consideraba hace tiempos relativamente recientes.

La investigadora israelí Zohar Shavit en una entrevista concedida en 2019, se refiere a la problemática postura de producción de las traducciones domesticadoras de literatura infantil en tiempos más remotos: 
I think it has changed in the sense that in the $19^{\text {th }}$ century and the beginning of the $20^{\text {th }}$ translators used the source texts as raw material. They had the liberty to do anything they wanted in order to adjust text to the target system. [...] This, however, is not the case anymore. Translators are more and more expected to produce full and adequate translations. As a case in point, I can bring my last study of domestication in translations into Hebrew, which I recently presented in a conference in Granada, Spain. There I have discussed how this norm predominated translations into Hebrew. [...] Everything was domesticated: first names, last names, foods, customs and holidays. [...] This norm is over. Translators are more and more expected nowadays to produce an adequate text and render the world presented in the source text without "converting" it. In this sense I think that major changes took place, at least in the literatures I study, although I cannot guarantee that it is true for other literatures. (2019, p. 263)

A partir de estas consideraciones iniciales de Shavit, surgieron otras reflexiones que nos hicieron discutir y elaborar un proyecto que tuviese como meta una traducción capaz de mostrar el Otro y sus especificidades culturales, la estructura textual y el ritmo de la lengua fuente. El objetivo era que estas "desfamiliarizaciones" ocasionales no afectasen la lectura del texto y que incluso pudiesen, sin perjuicio del sentido, despertar en el lector el interés por la cultura extranjera, en este caso, la cultura brasileña, en un contexto hispanohablante, particularmente el chileno. En esta misma línea de reflexión, trabajos como los de Torres y Debus (2016, p.12) destacan la importancia y necesidad de estas consideraciones al plantear las siguientes interrogantes "refletir sobre como levar a bagagem cultural, a cor local, a estranheza do original para a lingua/cultura de acolhimento, sem assustar ou intimidar o jovem leitor da cultura de chegada? Ou ainda que soluções podem ser consideradas para obter uma tradução que cumpra seu papel dentro do contexto de produção e recepção a que se destina?". 
Entendemos los polos de la dicotomía extranjerizar-domesticar como referentes puramente teóricos, que en sus extremos se vuelven abstracciones cuya realización es impracticable en el ejercicio de la traducción. No obstante, el hecho de que no sea plausible lograr el extremo de un polo no significa que no podamos tenerlo como horizonte y meta a la hora de elaborar un proyecto de traducción. Como traductores, estamos siempre oscilando en un eje imaginario entre estos dos polos, orientados a uno de ellos con mayor o menor intensidad. También somos conscientes de que existen muchas situaciones que pueden llevar una traducción por un camino fuertemente inclinado hacia un extremo o hacia el otro, ya sea por una posición definida por el traductor, o bien por razones editoriales y de otros actores involucrados en el proceso de traducción de la obra.

En este proyecto optamos por una traducción que priorizara la estructura, la forma y el estilo, además del sentido, por supuesto. Con esta propuesta buscamos evitar una traducción domesticadora del texto brasileño en español. Citamos aquí a Shavit (2016), quien se refiere al interesante ejemplo de la traducción al hebreo de J. H. Campe, realizada por Moshe Mendelssohn-Frankfurt y su explicación respecto a la toma de decisiones al traducirlo ${ }^{12}$.

Não reproduzi o livro palavra por palavra, porque isso não é útil; em vez disso, é longo demais. E tampouco mantive as palavras [originais], mas em vez disso o tema e as próprias ações. Aqui eu as tornei mais curtas, ali mais longas, e para tudo o que não pudesse ser feito na língua hebraica propus uma reprodução adequada, adaptada para nossa língua e suas próprias figuras de fala. Tornei mais longos vários pequenos assuntos [...]. ([citado en] Shavit (2016, p. 124, los subrayados son nuestros).

Moshe Mendelssohn-Frankfurt en la introducción a la traducción de Die Entdeckung von Amerika, de Campe (1807)

Cad. Trad., Florianópolis, v. 41, no 2 p. 221-246, mai-ago, 2021. 
Si bien es un ejemplo de otro contexto e idiomas, ilustra perfectamente bien lo que entendemos por una traducción domesticadora y destaca que esta estrategia de traducción tiene características opuestas a las que definimos como objetivo al traducir As Reinações de Narizinho al español de Chile. Como se explica en esta cita, las ampliaciones, las supresiones, los cambios de estructura, y el enfoque completo en las acciones y el tema (es decir, en el sentido y claridad del tema), son estrategias de traducción que pertenecen al ejemplo en cuestión $\mathrm{y}$, en términos generales, van en una dirección opuesta a nuestro proyecto de traducción. Si analizamos la traducción de Las travesuras de Naricita en Chile, veremos que se buscó evitar algunas "deformaciones bermanianas" (2014), recurrentes en las traducciones, ya que se evitó por todos los medios en el plano general del texto las adiciones, explicaciones y cambios de registros, entre otras tendencias a las que estamos expuestos de manera inconsciente o intencional.

\section{Análisis comparativo en función de algunas categorías seleccionadas}

Para este artículo seleccionamos algunas categorías y ejemplos que pueden ilustrar las estrategias usadas durante nuestro proceso de traducción y cuyo objetivo fue la aproximación al texto fuente. En este análisis priorizamos los neologismos, la estructura, el ritmo y los culturemas. Como recurso metodológico, cotejamos las seis traducciones, las que se disponen en dos tablas (por motivos de espacio) y que se ordenan cronológicamente de acuerdo con su fecha de publicación: 


\subsection{Neologismos}

Ejemplo 1: "Faminteza"

POR - texto fuente (2019, p. 09)

Não há peixe do rio que a não conheça; assim que ela aparece, todos acodem numa grande faminteza.

\begin{tabular}{|l|l|l|}
\hline ARG (1944, p. 10) & ARG (2010, p. 14) & PERÚ (2019, p. 6) \\
\hline $\begin{array}{l}\text { No hay pez en el río que } \\
\text { no la conozca; en cuanto } \\
\text { ella se sienta, acuden } \\
\text { todos presurosos, aun los } \\
\text { más alejados. }\end{array}$ & $\begin{array}{l}\text { No hay pez en el río que } \\
\text { no la conozca; en cuanto } \\
\text { acuden todos, aun los } \\
\text { más alejados. }\end{array}$ & $\begin{array}{l}\text { No hay pez en el río } \\
\text { que no la conozca, } \\
\text { ni bien llega, todos } \\
\text { acuden con apetito } \\
\text { voraz. }\end{array}$ \\
\hline $\begin{array}{l}\text { COL 1 (2019 JUNIO, } \\
\text { p. 6) }\end{array}$ & $\begin{array}{l}\text { COL 2 (2019 } \\
\text { OCTUBRE, p. 14) }\end{array}$ & CHILE (2020, p. 12) \\
\hline $\begin{array}{l}\text { No hay pez de río } \\
\text { que ella no conozca; } \\
\text { en cuanto aparece, } \\
\text { todos acuden con gran } \\
\text { familiaridad. }\end{array}$ & $\begin{array}{l}\text { No hay ningún pez } \\
\text { del río que no la } \\
\text { conozca; cuando ella } \\
\text { aparece, todos acuden } \\
\text { hambrientos. }\end{array}$ & $\begin{array}{l}\text { No hay pez en el río } \\
\text { por lo que, cuando } \\
\text { aparece, todos acuden } \\
\text { muy hambrosos. }\end{array}$ \\
\hline
\end{tabular}

La palabra faminteza no está formalmente incluida en varios diccionarios de lengua portuguesa, lo que se puede comprobar en una búsqueda en los principales de esta lengua (Aulete, Michaelis, Priberam, Houaiss, entre otros). Por lo tanto, se puede considerar la palabra como un neologismo. El origen de "faminteza" parece derivar de "faminto", ya sea en su sentido estricto o figurado. Según Aulete, "faminto" significa: 1. Que tem fome; ESFOMEADO. 2. Fig. Que anseia avidamente por algo; ÁVIDO: faminto de amor/ de glória/de honras 
Podríamos interpretar la palabra "faminteza" en un sentido figurado como alegría, de anhelo por algo y en este caso corresponde, entonces, recurrir al contexto más amplio del texto de partida para pensar en la traducción más adecuada. Sabemos que toda la historia de Naricita acontece en una zona rural (la parcela) y que Lobato utiliza en muchos textos el habla de la zona rural donde fue criado, es decir, del interior de São Paulo. La escena relatada en la obra ocurre a la orilla de un riachuelo: "Todas as tardes Lúcia toma a boneca e vai passear à beira d'água, onde se senta na raiz dum velho ingazeiro para dar farelo de pão aos lambaris. Não há peixe do rio que a não conheça; assim que ela aparece, todos acodem numa grande faminteza."

Por el contexto, se puede comprender que los peces se acercan justamente por el esmero con el que Naricita les lleva comida todas las tardes. La reconocen y se apresuran para conseguir su porción de migas de pan, ya que están condicionados a eso. Lo hacen alegre y ávidamente, y de esta manera la palabra faminteza funcionaría con este sentido de la alegría. Sin embargo, otra posibilidad es considerar el campo semántico del portugués "faminto-fomecomida" en el contexto de la escena. Pensamos, al principio, en la palabra "hambriento", que significa literalmente alguien con mucha hambre. No obstante, "hambriento" sería una traducción literal de "faminto", ambas palabras diccionarizadas, formales y de uso extendido, que son diferentes a la expresión y situación utilizadas en el texto fuente.

Si faminteza es un neologismo para definir un gran entusiasmo o para referirse a un grado de hambre (un neologismo para "esfomeado"), lo cierto es que es la elección léxica del autor la que transmite esta gracia y uso creativo del lenguaje. En la traducción teníamos la meta de mantener el aspecto estético del texto, los juegos de palabras, los ritmos, y, para el caso de los neologismos, crear otros en español, ya que la preocupación por el estilo textual era una condición de la traducción. Como es posible observar en las tablas, las cinco propuestas de traducción al español optaron por caminos diferentes para la traducción del pasaje "acodem numa grande faminteza". 
La primera traducción argentina, de 1944, refuerza la imagen de que todos los peces, sin excepción, se aproximan cuando ven a Naricita en la orilla del río. Por lo tanto, el traductor argentino destacó la presencia de todos los peces, incluso los que estaban más distantes. Sin embargo, la referencia a la palabra faminteza, ya sea en el sentido de alegría o de hambre, se perdió por completo. Eso se repite en la traducción de 2010 del mismo traductor, con la diferencia que la palabra "presurosos" fue eliminada en la nueva edición.

La traducción peruana optó por "apetito voraz", traduciendo la palabra "faminteza" en el campo semántico de "fome-faminto", sin considerar como prioridad la existencia del neologismo.

Por otro lado, las ediciones colombianas eligieron caminos diferentes para la traducción del término. Colombia 1 lo tradujo como "todos acuden con gran familiaridad". Al igual que la edición argentina, se omitió la palabra "faminteza" y se dio espacio a la idea de armonía entre la niña y los peces, además de destacar el hecho de que todos ya la conocían, que hay una familiaridad debido a que todas las tardes frecuentaba el mismo lugar. Colombia 2 tradujo "faminteza" por "hambriento", que, si bien está dentro del campo semántico que consideramos en nuestra traducción, en realidad es una traducción directa de la palabra "faminto", por lo que en este caso el neologismo también es ignorado.

Nuestra propuesta fue traducir el neologismo "faminteza" (asumiendo el escenario de entrega de comida por parte de Naricita) pensando en el sentido original de fome/hambre. Intentamos recrear el neologismo basándonos en la palabra en español "hambre", por lo que optamos por "hambroso". Esta palabra en español no es usada en contextos formales, en registros normativos y no aparece en las búsquedas directas de los diccionarios tradicionales como la Real Academia Española. Sin embargo, encontramos una instancia en que "hambroso" se usaría en un contexto oral como jerga de zonas rurales (similar al caso de la parcela de Naricita). Con esta definición: "hambroso, -a.I.1. adj. Ve. Referido a persona, hambrienta. rur" ${ }^{13}$, nos pareció la opción adecuada, ya que la

${ }^{13}$ https://lema.rae.es/damer/srv/search?id $=$ rzKY3dK7tx0AR9F1OvS.

Cad. Trad., Florianópolis, v. 41, no 2 p. 221-246, mai-ago, 2021. 
palabra no se encuentra en contextos normativos y al igual que "faminteza", es un neologismo que proviene de la palabra "hambre/ fome" y se mantiene en este mismo campo semántico que encaja perfectamente el contexto.

\subsection{Estructura, ritmo y juegos de palabras}

\section{Ejemplo 2:}

\section{POR - texto fuente (2019, p. 22)}

E canários cantando, e beija-flores beijando as flores, e camarões camaronando, e caranguejos caranguejando, tudo que é pequenino e não morde, pequeninando e não mordendo.

\begin{tabular}{|c|c|c|}
\hline ARG (1944, p. 34) & ARG (2010, p. 29) & PERÚ (2019, p. 20-21) \\
\hline $\begin{array}{l}\text { Y canarios cantando, } \\
\text { y picaflores picando } \\
\text { las flores y camarones } \\
\text { camaroneando y } \\
\text { cangrejos andando } \\
\text { para atrás. Todo } \\
\text { lo pequeñito e } \\
\text { incapaz de morder } \\
\text { empequeñeciéndose } \\
\text { más y paseándose. }\end{array}$ & $\begin{array}{l}\text { Y canarios cantando, } \\
\text { y picaflores picando } \\
\text { las flores y camarones } \\
\text { camaroneando y } \\
\text { cangrejos andando } \\
\text { para atrás. Todo } \\
\text { lo pequeñito e } \\
\text { incapaz de morder } \\
\text { empequeñeciéndose y } \\
\text { no mordiendo. }\end{array}$ & $\begin{array}{l}\text { Y canarios cantando, } \\
\text { colibriés, picando } \\
\text { las flores, camarones } \\
\text { camaroneando y cangrejos } \\
\text { cangrejeando. Todo } \\
\text { lo que es pequeñito } \\
\text { e incapaz de morder } \\
\text { empequeñeciéndose más y } \\
\text { no picando. }\end{array}$ \\
\hline $\begin{array}{l}\text { COL 1(2019 JUNIO, } \\
\text { p. 26) }\end{array}$ & $\begin{array}{l}\text { COL } 2 \text { (2019 } \\
\text {-OCTUBRE, p. 38) }\end{array}$ & CHILE (2020, p. 49) \\
\hline $\begin{array}{l}\text { Y canarios cantando, } \\
\text { y picaflores picando } \\
\text { flores, y camarones } \\
\text { camaronando, y } \\
\text { cangrejos cangrejando, } \\
\text { y todo lo que es } \\
\text { pequeñito y no muerde, } \\
\text { pequeñitando y no } \\
\text { mordiendo. }\end{array}$ & $\begin{array}{l}\text { Y los canarios } \\
\text { cantaban, los picaflores } \\
\text { besaban las flores, } \\
\text { y los camarones } \\
\text { camaroneaban, y los } \\
\text { cangrejos cangrejeaban, } \\
\text { y todo lo que es } \\
\text { pequeñito y no muerde, } \\
\text { pequeñeaba sin morder. }\end{array}$ & $\begin{array}{l}\text { Y canarios cantando, } \\
\text { y picaflores picando } \\
\text { flores, y camarones } \\
\text { camaroneando y } \\
\text { cangrejos cangrejeando, y } \\
\text { todo lo que es pequeñito y } \\
\text { no muerde, pequeñeando } \\
\text { y no mordiendo. }\end{array}$ \\
\hline
\end{tabular}


En el episodio "A festa e o Major", Naricita se dirige al salón de baile y queda impresionada al ver a los pintorescos invitados. Para describir la diversidad y el color de estos, Lobato despliega la gramática del portugués de una forma lúdica y creativa. Como se puede apreciar en la tabla, hay una deliberada repetición de seis gerundios que marcan un ritmo particular, además de generar rimas consonantes que le otorgan una musicalidad especial al párrafo. Por estas razones, el lector en esta escena toma consciencia de aspectos rítmicos y estructurales del portugués. Junto con esto, Lobato juega con la estructura de su idioma y crea los términos "camaroneando" y "pequeninando", los cuales no están diccionarizados (en Aulete, Michaelis, Priberam y Houaiss) pero se logran comprender con toda naturalidad. Es así como Lobato reluce el potencial rítmico y estructural de su lengua, y, en particular, utiliza los gerundios para desarrollar un efecto estético.

No es casualidad que en esta escena la gramática del portugués se vuelva colorida y creativa. Por medio de la reiteración de los gerundios, Lobato logra transmitir la velocidad e impacto con la que Naricita "recorrió con sus ojos a los asistentes." También, al darle giros creativos a palabras como "pequenino" y "camaroneando", el escritor nos transmite la sensación de asombro y curiosidad de Naricita: el lenguaje se rompe y se ajusta en la medida en que Naricita no logra asimilar del todo el mundo nuevo que está descubriendo. Recordemos que solo unas líneas antes se utiliza la expresión "Uma verdadeira tontura de beleza" (Lobato, 2019, p. 22) para referirse al vértigo con el cual Naricita descubre el salón de baile, vértigo que pareciese afectar a la misma gramática del lenguaje.

Como se aprecia en los cuadros, las distintas traducciones discrepan principalmente en tres puntos: la conservación de los gerundios; el ritmo en relación con las comas o puntos; y la estrategia de traducción para "pequeninando e não mordendo."

La versión peruana opta por mantener parcialmente los gerundios: "nao mordendo" y "pequeninando" se traducen como "incapaz de morder" y "empequeñeciéndose más", lo que subordina el uso 
creativo del original a la gramática normativa del español, y corta la cadencia de gerundios y altera el ritmo de la lectura original.

Al igual que la versión peruana, la edición argentina de 1944 optó por un lenguaje más convencional en el cual se introduce una pausa mediante un punto y se omiten los gerundios finales. A diferencia de la edición peruana, en su estrategia de traducción se mantiene la rima final, entre "empequeñeciéndose" y "paseándose". Una decisión que solo esta versión consideró, es la traducción de "caranguejando" como "andando para atrás". "Caranguejando" aquí se interpreta como el movimiento característico de los cangrejos en lugar de dejarle al lector la decisión de imaginar el significado de "caranguejando". La edición argentina de 2010 solo se diferencia de la de 1944 en la traducción de "não mordendo" y en la omisión del "más" después de "empequeñeciéndose". En lugar de "paseándose", la edición argentina de 2010 opta por "y no mordiendo", por lo que se pierde la rima final. Sin embargo, al recuperar el uso del gerundio esta edición se acerca más a la estructura y ritmo del texto fuente.

La propuesta de Colombia 1 comparte las prioridades de la versión chilena: se mantiene la estructura y la cadencia de los gerundios. Las diferencias son, de hecho, sutiles, y dan cuenta de la diferente manera en que se realiza la conversión desde sustantivo o adjetivo a gerundio: camaronando/camaroneando y cangrejando/ cangrejando, y "pequeñitando" y "pequeñeando".

En Colombia 2, podemos apreciar la particularidad de que los gerundios (que en mayor o menor cantidad se mantienen en todas las otras versiones) se traducen como pretéritos imperfectos. Cabe destacar que se traducen todos y de manera consistente, generando así un ritmo propio.

En la traducción chilena quisimos conservar lo más cerca posible estos aspectos rítmicos y estructurales del portugués, y buscamos transmitir la estética que estos aspectos configuran en la obra original. Por esta razón, decidimos mantener el uso de gerundios "cantando", "camaroneando", "cangrejeando" y "no mordiendo", a la vez que conservamos el giro de "pequeñito" a 
"pequeñeando". Por lo demás, a modo de transmitir la velocidad y la sensación de cadencia del párrafo original, decidimos mantener también las comas en lugar de marcar una pausa mayor o sustituir alguna con un punto.

\subsection{Culturemas}

\section{Ejemplo 3:}

POR - texto fuente $(2019$, p. 33)

Felizmente era tempo de jabuticabas.

[...] E a música da jabuticabeira era assim:

\begin{tabular}{|l|l|l|}
\hline ARG (1944, p 51) & ARG (2010, p. 43) & PERÚ (2019, p. 31-32) \\
\hline $\begin{array}{l}\text { Felizmente era época de } \\
\text { guindas. } \\
\text { [...] Y la música de la } \\
\text { guinda era entonces así: }\end{array}$ & $\begin{array}{l}\text { Felizmente era tiempo de } \\
\text { jaboticabas } \\
{[\ldots] \text { Y la música de la }} \\
\text { jaboticabera era entonces } \\
\text { así }\end{array}$ & $\begin{array}{l}\text { Felizmente era época de } \\
\text { jaboticabas. } \\
{[\ldots] \text {... la música de las }} \\
\text { jaboticabas era así: }\end{array}$ \\
\hline COL 1(2019 JUNIO) & $\begin{array}{l}\text { COL 2 (2019 } \\
\text { OCTUBRE, p. 52 y 54) }\end{array}$ & CHILE (2020, p. 58) \\
\hline $\begin{array}{l}\text { Sin traducción del } \\
\text { capítulo 2 }\end{array}$ & $\begin{array}{l}\text { Afortunadamente era la } \\
\text { época de los corozos. } \\
{[\ldots] \text { Y la canción del }} \\
\text { corozos era así: }\end{array}$ & $\begin{array}{l}\text { Afortunadamente, } \\
\text { era tiempo de las } \\
\text { jabuticabas. } \\
{[\ldots] \text { Y la música de la }} \\
\text { jabuticabeira era así: }\end{array}$ \\
\hline
\end{tabular}

Para no profundizar en las varias definiciones y clasificaciones de culturemas, partimos directamente con la definición clásica de Vermeer, en la cual se establece que un culturema es: "Un fenómeno social de una cultura X que es entendido como relevante por los miembros de esa cultura, y que comparado con un fenómeno 
correspondiente de una cultura $\mathrm{Y}$, resulta ser percibido como específico de la cultura X." (Vermeer, 1983, p.8).

Se entiende que los culturemas jabuticaba y jabuticabeira son extremadamente relevantes en la cultura brasileña, y merecen ser destacados en el libro Reinações de Narizinho. El capítulo dos, "La Parcela del Pájaro Carpintero Amarillo”, precisamente comienza con el cuento "Las jabuticabas". En él, se relatan las aventuras de la niña Naricita en el árbol de la jabuticabeira y el extenso tiempo que el personaje dedica a comer la fruta al pie del árbol.

En una publicación de $2015^{14}$ la EMBRAPA (organización gubernamental vinculada al Ministerio de Agricultura, Ganadería y Abastecimiento de Brasil) aclara el origen de la jabuticaba: "Conhecida há mais de 400 anos, a jabuticaba é 100\% nativa da Mata Atlântica brasileira. [...] De origem indígena, foi denominada pelos tupis de "iapoti kaba", que significa "frutas em botão".

Analicemos, entonces, las opciones de traducción de los culturemas en las ediciones en español. La edición argentina de 1944 optó por traducir jabuticaba como guinda, un referente más amplio y común en muchas partes del mundo, proveniente de la familia rosaceae y conocida también como cereza y cereza silvestre, entre otras denominaciones. Se trata de una fruta que puede tener semejanzas con la jabuticaba por su forma redonda y pequeño tamaño, pero con un color rojizo o rojo intenso que la aleja de la imagen de la fruta tropical brasileña negra, y su sabor más ácido también se contrapone al dulzor de la jabuticaba. La traducción de jabuticaba por guinda no se refiere a una fruta nativa argentina, pero conduce al lector a una imagen más conocida para su público, de frutos rojos, algo que se acomoda a la manera suave de ver la cultura extranjera, lo que elimina el referente brasileño. Ya la edición de 2010, del mismo traductor, presenta el culturema "jaboticaba" en portugués y agrega una nota al pie: "Fruta muy

14 https://www.embrapa.br/busca-de-publicacoes/-/publicacao/1027136/valornutricional-da-jabuticaba.

Cad. Trad., Florianópolis, v. 41, n⿳2 2 p. 221-246, mai-ago, 2021. 
apreciada en el Brasil, jugosa, de cáscara negra y brillante, del tamaño de las cerezas" (Lobato, 2010, p. 43)

Sobre la jabuticabeira, el árbol que produce la jabuticaba, notamos que hay un problema de sentido en la traducción de la palabra en la edición de 1944. El narrador en portugués dice: "E a música da jabuticabeira era assim: tloc, pluf, nhoc, tloc, pluf, nhoc ...”. A través onomatopeyas, aquí se relata la dinámica a través de la cual se presenta la escena, es decir, la niña chupando la jabuticaba y la explosión de la fruta en la boca tan conocida por los brasileños (tloc), el gesto de escupir el cuesco (pluf) y el lechoncito que espera ansioso y luego se lo engulle (nhoc). La "música del árbol" es una referencia a la secuencia completa de la escena de la jabuticabeira, y cuenta el proceso de cómo Naricita come la fruta y escupe el cuesco, y de cómo el lechoncito se engulle este último. Por lo tanto, traducir el árbol de la jabuticabeira por la fruta guinda no es precisamente adecuado, pues eso no es lo que se dice en portugués. Para mantener esa coherencia con el texto fuente y la mención del árbol (y manteniendo la opción argentina) entonces debería ser: "Y la música del guindo era entonces así". La edición de 2010 corrige el problema de sentido traduciendo el fragmento como "la música de la jaboticabera", y aunque no utilice la palabra en portugués con la grafía correcta, o sea, jaboticabeira o jabuticabeira, mantiene el extranjerismo que pertenece a la cultura fuente.

La edición peruana sigue caminos interesantes para tratar el culturema en la traducción, ya que mantiene el préstamo puro "jaboticabas" en la frase: "Felizmente era época de jaboticabas". Al mismo tiempo que mantiene el léxico extranjero, incluye una nota al pie de página, haciendo entonces uso de la técnica de amplificación, que según Hurtado es cuando "se introducen precisiones no formuladas en el texto original: informaciones, paráfrasis explicativas, notas del traductor, etc". (Hurtado, 2013, p. 269). En la nota al pie de página de la edición encontramos: "Fruto de la jabuticabeira, árbol perteneciente a la familia de las mirtáceas encontrado en Brasil. Los frutos crecen aglomerados 
en el tronco y en las ramas más gruesas. Son de color morado al principio y más negras al madurar”. Además de la nota, la edición ofrece un paratexto visual (Lobato, 2019a, p. 30), en una escena bastante conocida de Naricita trepada en el árbol de la jabuticabeira (con las jabuticabas pegadas al tronco). En esta misma edición de Perú, en la segunda parte escogida como ejemplo para el cotejo, vemos que se traduce el árbol por la fruta de la jaboticaba, cuando idealmente debería ser la palabra jaboticabeira, siguiendo la lógica y grafía de la traducción peruana.

Sobre las ediciones publicadas en Colombia, Colombia 1 no llega a traducir el segundo capítulo, en el cual se hace mención directa a la fruta y el árbol de la jabuticabeira. Colombia 2 optó por usar un referente local: la fruta "corozo", que se encuentra en el caribe colombiano y que en realidad crece en una palmera y que, por lo tanto, en nada se asemeja a la jabuticabeira, donde el personaje de Lobato pasa horas y horas en la versión en portugués.

Varias investigaciones académicas colombianas en el área de las ciencias biológicas, como la realizada por el docente Dr. Luis Alberto Avellaneda ${ }^{15}$, de la Universidad de La Salle (Bogotá), nos brindan información sobre el "corozo" en la cultura colombiana, que es lo que en Brasil se conoce como macaúba. Está claro que la jabuticabeira de la Parcela y la palmera de la macaúba no pertenecen a la misma familia, ni tampoco se asemejan en la forma, ni en las características de sus frutas, jabuticaba y coco de macaúba respectivamente, como tampoco se asemejan en consistencia ni en sabor. Es interesante notar que la edición colombiana ofrece para este pasaje de la jabuticabeira, la cual se trata como “árbol del corozo", una imagen de Naricita trepada en un árbol estilizado (Lobato, 2019c, pág. 53), que en verdad busca una aproximación

\footnotetext{
15 https://www.utopia.edu.co/Noticias/InvestigacionPertinente/uls/Potencial + de + la + palma + del + corozo + costeno + una + palmera + de + importancia + econo mica $\% 2 \mathrm{C}+$ ecologica $+\mathrm{y}+$ cultural $+\mathrm{en}+\mathrm{el}+$ mercado + colombiano. Para más detalles sobre la investigación https://www.sciencedirect.com/science/article/abs/ pii/S0367253020301286.
} 
ilustrativa con un árbol frondoso, repleto de hojas y que se distancia mucho de la palmera en apariencia, aunque tampoco proyecta la imagen de una jabuticabeira, ya que las frutas aparecen mezcladas con las hojas, y no están pegadas al tronco, como es característico de esta especie. Exactamente como en la traducción argentina de 1944 y la peruana, la edición colombiana utilizó el fruto en lugar del árbol para traducir jabuticabeira, que, en este caso, idealmente sería "Y la canción del árbol del corozo".

En la edición chilena, optamos por preservar en el texto español los dos culturemas, jabuticaba y jabuticabeira, y ofrecemos como paratexto visual una escena de Naricita en el árbol, que figura como una ilustración de página completa (Lobato, 2020, p. 59) y aparece exactamente cuándo se menciona la fruta por primera vez, la cual aparece: "Afortunadamente, era tiempo de las jabuticabas" (ibidem, p. 58). Posteriormente encontramos: "En la parcela de Doña Benta había varios árboles" (ibidem, p. 60). También escogimos esta misma imagen para ilustrar la portada del libro, con la idea de despertar la curiosidad de los niños y niñas desde el inicio, y para que pudiesen familiarizarse con el árbol, que podría ser desconocido y exótico debido a que sus frutos están pegados al tronco.

\section{Consideraciones finales}

A partir de nuestra estrategia de traducción y aproximación al texto fuente, buscamos evaluar, caso por caso, los diferentes contextos y desafíos que surgieron en la traducción de Reinações de Narizinho. Como hemos dicho, nuestro propósito fue presentar una obra traducida que contribuyese a la inserción de la literatura infantil brasileña en Chile y destacar los valores y diferencias de otras culturas, así como preservar aspectos estructurales del texto de partida en lengua portuguesa. Nuestro objetivo principal siempre fue reconocer al Otro en su calidad de otro.

Por medio de los ejemplos analizados en este artículo es posible notar algunas estrategias que validan nuestro objetivo principal. 
Volvemos aquí al caso de la preservación de la puntuación y repetición de gerundios (ejemplo 2), que fue consciente y analizado a partir de las reflexiones de Berman (2014), quien nos recuerda que una de las tendencias deformantes intrínsecas del ejercicio de la traducción es la racionalización, es decir, el cambio de las estructuras sintácticas del texto de partida por parte del traductor. Según Berman, la gran prosa: "tiene, lo dijimos brevemente, una estructura en arborescencia (repeticiones, proliferación en cascada de las relativas y de los participios, incisos, frases largas, frases sin verbos, etc.) que es diametralmente opuesta a la lógica lineal del discurso en tanto discurso. La racionalización reduce violentamente el original de su arborescencia a la linealidad." (Berman, 2014, p. 56)

Buscamos, entonces, mantener la arborescencia acercándonos lo más posible al texto de partida. También recibieron especial atención los neologismos, como indicamos en el ejemplo de faminteza.

El caso de los culturemas jabuticaba y jabuticabeira también puede ilustrar nuestras aspiraciones durante el proceso de traducción. Sabemos que mantener la cercanía a la cultura de partida o la preservación de ciertas palabras extranjeras en el texto traducido son opciones editoriales válidas. Comparando las ediciones argentinas de 1944 y 2010, la peruana, la chilena y Colombia 2, nos damos cuenta de que cada una de ellas ha optado por un punto de partida distinto en relación a la traducción de la fruta. La edición argentina de 1944 escogió la fruta "guinda" para la traducción de jabuticaba, utilizando un referente cultural más general; la edición argentina de 2010 prefirió mantener la “jaboticaba” y agregó una nota al pie de página que indica el origen del término extranjero, tal cual lo hizo la edición peruana que además de mantener la palabra en portugués también ofrece una imagen de apoyo muy parecida a una jabuticabeira que puede ayudar al lector a reconocer algo ajeno a su cultura. Colombia 2 optó por una fruta proveniente de una palmera encontrada en su hábitat natural, el "corozo".

Para la traducción del árbol, como se puede ver en el fragmento 
comparado, las ediciones argentina (1944), peruana y colombiana no tradujeron la jabuticabeira con los nombres de los árboles respectivos. Según las frutas escogidas, estos serían el guindo para la argentina de 1944, la jaboticabeira para la peruana, y el árbol del corozo para la colombiana. La edición de 2010 de Argentina hace la corrección de sentido y usa el nombre del árbol en lugar de la fruta, aunque la grafía no sea la adecuada en portugués. Nuestra edición chilena escogió preservar el culturema tal cual se presenta en el texto fuente en ese pasaje específico, haciendo uso de un préstamo puro y preservando no solo el sentido de la frase (que indica el árbol en lugar del fruto) sino también presentando el elemento cultural brasileño.

A modo de conclusión, esperamos seguir con las reflexiones en ejemplos posteriores y con el análisis de cada caso particular, y deseamos explorar en un próximo estudio diferentes categorías y desafíos, como es el caso de la traducción de palabras sensibles en textos infantiles.

\section{Referencias}

Albieri, Thaís de Mattos. São Paulo-Buenos Aires- trajetória de Monteiro Lobato na Argentina. 2009. 318 p. Tese (doutorado) - Universidade Estadual de Campinas. Instituto de Estudos da Linguagem, Campinas, SP. Disponible en: < http://www.repositorio.unicamp.br/handle/REPOSIP/270113>. Acceso en: 21 de diciembre 2020.

Berman, Antoine. La traducción y la letra o el albergue de lo lejano. 1.a ed. Trad. Ignacio Rodríguez. Buenos Aires: Dedalus, 2014.

Debus, Eliana Santana y Torres, Marie Hélène. Sobre a tradução de livros infantis 
e juvenis. Cadernos de Traducao, v. 36 n. 1 (2016): Edição Regular - temática: Literatura Infantil e juvenil. Acceso 13 de enero de 2021. Disponible en: https:// periodicos.ufsc.br/index.php/traducao/article/view/2175-7968.2016v36n1p10.

Hurtado, Albir. Traducción y traductología: introducción a la traductología. $6^{\mathrm{a}}$ edición. Madrid: Cátedra, 2013.

Lobato, Monteiro. Reinações de Narizinho. (Org.) Marisa Lajolo. São Paulo: Companhia das Letrinhas, 2019 [1931].

Lobato, Monteiro. Las travesuras de Naricita. Trad Ramón Prieto. Buenos Aires Editorial Americalee, 1944.

Lobato, Monteiro. Las travesuras de Naricita. Trad Ramón Prieto. Buenos Aires Editorial Losada, 2010.

Lobato, Monteiro. Las travesuras de Naricita. Lima: Cantarera editores, 2019a.

Lobato, Monteiro. Las travesuras de Naricita. Trad Elkin Obregón. Colección Leer es mi cuento. Bogotá: Ministerios de Educación y Cultura de Colombia, $2019 b$.

Lobato, Monteiro. Naricita impertinente y La casa del pájaro carpintero amarillo. Trad. Mariana Serrano. Bogotá: Instituto Distrital de las Artes - Idartes, 2019c.

Lobato, Monteiro. Las travesuras de Naricita. Trad. Letícia Goellner, Pablo Saavedra, Vicente Menares. Pontificia Universidad Católica de Chile. Ediciones UC: Santiago, 2020

Shavit, Zohar. Tradução cultural: ajustes ideológicos e de modelo na tradução de literatura infantil. Belas Infiéis, v. 5. n. 3, p. 119-143 (2016). Acceso 13 de enero de 2021. Disponible en: https://periodicos.unb.br/index.php/belasinfieis/article/ view/11403. 
Shavit, Zohar. Interview with Zohar Shavit, por Lia Lima. Belas Infiéis, v.8. n.3, p. 257- 276 (2019). Acceso 02 de enero de 2021. Disponible en: https:// periodicos.unb.br/index.php/belasinfieis/article/view/26342.

Vermeer, H. Translation theory and linguistics. En Roinila, P., Orfanos, R. \& Tirkkonen-Condit, S. (Eds.), Näkökohtia käänämisen tutkimuksesta. Joensuu: University of Joensuu, 1983.

Recebido em: 20/01/2021 Aceito em: 28/03/2021 Publicado em maio de 2021

Leticia Goellner. E-mail leticia.goellner@uc.cl. ORCID: https://orcid.org/00000001-5662-1672.

Pablo Saavedra. E-mail pisaaved@uc.cl. ORCID: https://orcid.org/0000-00015192-9993.

Vicente Menares. E-mail vjmenares@uc.cl ORCID: https://orcid.org/0000-00020626-1143. 